Correspondence

Bo-Moon Shin

bmshin@unitel.co.kr

Received 18 November 2007 Accepted 19 March 2008

\section{Multicentre study of the prevalence of toxigenic Clostridium difficile in Korea: results of a retrospective study 2000-2005}

\author{
Bo-Moon Shin, ${ }^{1,2}$ Eun Young Kuak, ${ }^{1}$ Hyeon Mi Yoo, ${ }^{2}$ Eui Chong Kim, ${ }^{3}$ \\ Kyungwon Lee, ${ }^{4}$ Jung-Oak Kang, ${ }^{5}$ Dong Hee Whang ${ }^{6}$ \\ and Jeong-Hwan Shin ${ }^{7}$
}

\author{
${ }^{1}$ Department of Laboratory Medicine, Sanggye Paik Hospital, Inje University, Seoul, \\ Republic of Korea \\ ${ }^{2}$ Office of Infection Control, Sanggye Paik Hospital, Inje University, Seoul, Republic of Korea \\ ${ }^{3}$ Department of Laboratory Medicine, Seoul National University, Seoul, Republic of Korea \\ ${ }^{4}$ Department of Laboratory Medicine, Yonsei University, Seoul, Republic of Korea \\ ${ }^{5}$ Department of Laboratory Medicine, Hanyang University, Kuri, Republic of Korea \\ ${ }^{6}$ Department of Laboratory Medicine, Seoul Paik Hospital, Seoul, Republic of Korea \\ ${ }^{7}$ Department of Laboratory Medicine, Busan Paik Hospital, Busan, Republic of Korea
}

The prevalence of toxigenic Clostridium difficile in Korea has been reported to be approximately $60-80 \%$. Although the prevalence of the $t c d A^{-} t c d B^{+}$C. difficile strain was less then $5 \%$ prior to the year 2000, it has become an emerging nosocomial pathogen in Korea. Therefore, we have attempted to determine the multicentre nationwide prevalence of $t c d A^{+} t c d B^{+}$and $t c d A^{-} t c d B^{+}$ C. difficile for epidemiological purposes. C. difficile strains $(n=724,30$ from 2000, 80 from 2001, 74 from 2002, 76 from 2003, 179 from 2004, 285 from 2005) were obtained retrospectively from January 2000 to December 2005 from in-patients at 6 hospitals, all of whom were suspected of having C. difficile-associated disease (CDAD), colitis or pseudomembranous colitis. The numbers of participating hospitals varied yearly (1 in 2000, 2 in 2001-2003, 3 in 2004, 5 in 2005). The hospitals were located in Seoul $(n=4)$, Kyunggi Province $(n=1)$ and Busan $(n=1)$, Korea. PCR assays for $t c d A$ and $t c d B$ genes were conducted using 724 unduplicated $C$. difficile isolates. The mean prevalence of $t c d A^{+} t c d B^{+}$and $t c d A^{-} t c d B^{+}$C. difficile strains over the 6 years was $51.8 \%$ (38.4-59.3\%) and $25.8 \%(10-56.0 \%)$, respectively. The mean prevalence of $t c d A^{-} t c d B^{+} C$. difficile strains was less than $7 \%$ until 2002, but began to increase in $2003(13.2 \%)$ and achieved a peak in 2004 (50.3\%). In 2005, the mean prevalence of $t c d A^{+} t c d B^{+}$and tcd $A^{-} t c d B^{+}$C. difficile strains was $47.7 \%(30.9-60.3 \%)$ and $27.0 \%(17.6-54.8 \%)$, respectively. This nationwide epidemiological study showed that $t c d A^{-} t c d B^{+} C$. difficile strains have already spread extensively throughout Korea, and our results provide basic data regarding the controversies currently surrounding the toxigenicity of $t c d A^{-} t c d B^{+} \mathrm{C}$. difficile. The use of enzyme immunoassays capable of detecting both $\mathrm{Tcd} A$ and $\mathrm{TcdB}$ is strongly recommended for the diagnosis of CDAD in microbiology laboratories, in order to control the spread of the tcd $A^{-} t c d B^{+}$strains of $C$. difficile.

\section{INTRODUCTION}

Clostridium difficile is one of the most common nosocomial pathogens and is responsible for $C$. difficile-associated

Abbreviations: CDAD, Clostridium difficile-associated disease; EIA, enzyme immunoassay; PaLoc, pathogenicity locus; PMC, pseudomembranous colitis. disease (CDAD) and pseudomembranous colitis (PMC). C. difficile can be either toxigenic or non-toxigenic. Toxigenic C. difficile strains generally produce an enterotoxin (TcdA) and a cytotoxin $(\mathrm{TcdB})$. These toxins are encoded by two genes, $t c d A$ and $t c d B$, which have been mapped to a $19.6 \mathrm{~kb}$ chromosomal pathogenicity locus (PaLoc) (Rupnik et al., 1998). Besides both of these genes, three additional 
regulatory genes $(t c d C, t c d D$ and $t c d E)$ are located within the PaLoc (Braun et al., 1996; Hammond \& Johnson, 1995; Cohen et al., 2000). However, a number of different genetic variants of $C$. difficile have been reported with increasing frequency worldwide. $C$. difficile strains with various genetic modifications within the PaLoc have been studied in the past, and 28 different toxinotypes have been identified (Rupnik et al., 1998). These include variants of C. difficile that harbour deletions, insertions or polymorphic restriction sites in one or more of the genes within the PaLoc, but still generate functional TcdA and TcdB toxins $\left(\mathrm{TcdA}^{+} \mathrm{TcdB}^{+}\right.$strains). However, strains of toxinotypes VIII, X, XVI and XVII generate a functional TcdB but no $\mathrm{TcdA}\left(\mathrm{TcdA}^{-} \mathrm{TcdB}^{+}\right.$strains), whereas strains grouped into toxinotype XI harbour only the $3^{\prime}$ portion of $t c d A$ and generate neither TcdA nor TcdB ( $\mathrm{TcdA}^{-} \mathrm{TcdB}^{-}$strains) (Von Eichel-Streiber et al., 1999; Rupnik et al., 1997; Rupnik, 2001). Until recently, it was believed that all $C$. difficile strains responsible for diseases generated both TcdA and TcdB, which functioned synergistically. However, a great many recent studies have shown that $\mathrm{TcdA}^{-} \mathrm{TcdB}^{+}$strains are involved in a wide spectrum of $\mathrm{CDAD}$ ranging from colonization, to uncomplicated diarrhoea to PMC (Brazier et al., 1999; Al-Barrak et al., 1999; Alfa et al., 2000; Limaye et al., 2000; Johnson et al., 2001; Kuijper et al., 2001; Pituch et al., 2001).

The prevalence rates of these $\mathrm{TcdA}^{-} \mathrm{TcdB}^{+}$strains were reported as ranging from 0.2 to $56 \%$ in different studies from the USA, Europe and Asia (Kato et al., 1998; Lyerly et al., 1998; Pituch et al., 2001; Barbut et al., 2002; Samra et al., 2002; Rupnik et al., 2003; Geric et al., 2004). However, as the $\mathrm{TcdA}^{-} \mathrm{TcdB}^{+} C$. difficile prevalence rate has been reported to be as high as $39 \%$ in one Japanese study (Komatsu et al., 2003) and a highly prevalent $\mathrm{TcdA}^{-} \mathrm{TcdB}^{+}$C. difficile strain was detected in a tertiary hospital in Korea, this variant strain has become recognized as an emerging pathogen in Korea (Shin \& Kuak, 2006; Shin et al., 2008). Therefore, it is important to determine at what time the $\mathrm{TcdA}^{-} \mathrm{TcdB}^{+} C$. difficile strains became prevalent and when they really began to be widely distributed throughout Korea. In this study, we have investigated the nationwide prevalence of $\mathrm{TcdA}^{+} \mathrm{TcdB}^{+}$ and $\mathrm{TcdA}^{-} \mathrm{TcdB}^{+}$C. difficile strains in Korea from 2000 to 2005 for epidemiological purposes.

\section{METHODS}

Specimens. A total of 724 strains of C. difficile (30 from 2000, 80 from 2001, 74 from 2002, 76 from 2003, 179 from 2004, 285 from 2006) were obtained between January 2000 and December 2005 from in-patients at 6 hospitals suspected of harbouring CDAD, colitis or PMC. The numbers of participating hospitals varied yearly ( 1 in 2000 , 2 in 2001-2003, 3 in 2004, 5 in 2005). The hospitals were located in Seoul $(n=4)$, Kyunggi Province $(n=1)$ and Busan $(n=1)$, Korea, and the mean number of beds was 920 , with a range of 400-2000 (Fig. 1).

C. difficile cultures. Stool samples collected from patients suspected to be infected with $C$. difficile were inoculated into anaerobically

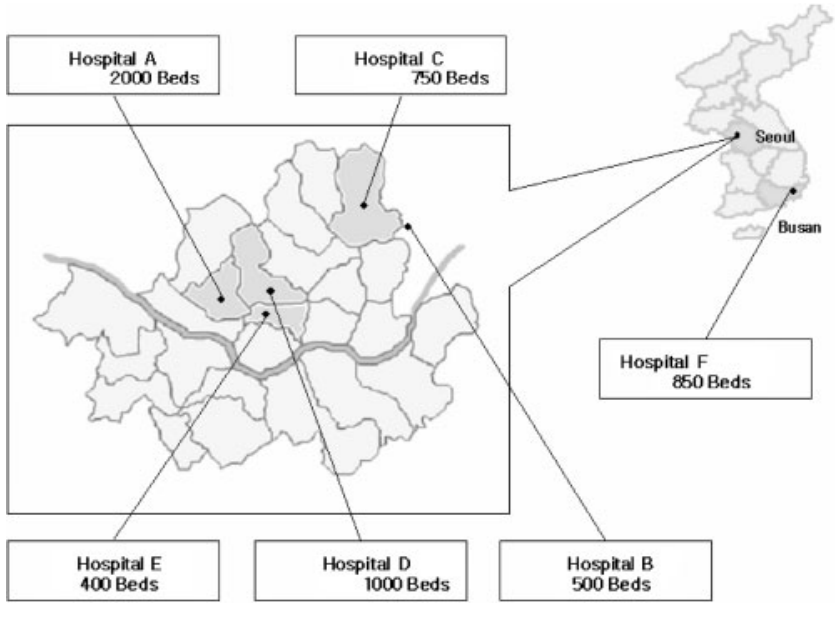

Fig. 1. The location and number of beds for each of the six participating hospitals.

reduced cycloserine-cefoxitin-fructose agar at $37{ }^{\circ} \mathrm{C}$ under anaerobic conditions for $48-72 \mathrm{~h}$ in each participating hospital. The identification of $C$. difficile was conducted in each participating laboratory in accordance with local techniques, which included analysis of Gram stain, spore stain, characteristic odour and typical morphological features, and/or enzyme immunoassays (EIAs) to detect TcdA. Isolates sent to the central coordinating laboratory were then subcultured, and identification was confirmed via a biochemical assay using an ANA identification test kit (bioMérieux).

PCR assay for $\boldsymbol{t} \mathbf{c d} \boldsymbol{A}$ and $\boldsymbol{t} \boldsymbol{c d} \boldsymbol{B}$. Genes that encode the large clostridial toxins A and B ( $t c d A$ and $t c d B$ ) were detected by PCR in accordance with the methods described by Kato et al. (1998), with some modifications, on 724 strains of $C$. difficile. Template DNA was prepared by suspending 20 colonies in a $5 \%(\mathrm{w} / \mathrm{v})$ solution of Chelex100 (Bio-Rad), boiling for $12 \mathrm{~min}$, then centrifuging for $5 \mathrm{~min}$ at $12000 \mathrm{~g}$. The total volume of the PCR reaction was $100 \mu \mathrm{l}$, and it contained $\sim 30 \mathrm{ng}$ bacterial DNA preparation, $0.15 \mu \mathrm{g}$ each primer, the four dNTPs $(200 \mu \mathrm{M}$ each), $10 \mathrm{mM}$ Tris/ $\mathrm{HCl}(\mathrm{pH} 8.3), 2.5 \mathrm{mM}$ $\mathrm{MgCl}_{2}, 50 \mathrm{mM} \mathrm{KCl}$ and $2.5 \mathrm{U}$ Taq polymerase. $t c d A$ and $t c d B$ were amplified using the following primers: NK9 (5'-CCACCA GCTGCAGCCATA-3') and NK11 (5'-TGATGCTAATAATGAA TCTAAAATGGTAAC- $3^{\prime}$ ), which were derived from the repeating sequence of $t c d A$; and primers NK104 (5'-GTGTAGCAATGAAA GTCCAAGTTTACGC-3') and NK105 (5'-CACTTAGCTCTTT GATTGCTGCACCT- $3^{\prime}$ ), which were derived from the non-repeating sequence of $t c d B$, respectively. The ATCC 43596 strain (serogroup C) was utilized as the $t c d A^{+} t c d B^{+}$control and ATCC 43598 strain (serogroup F) was used as the $t c d A^{-} t c d B^{+}$variant control. PCR amplification using $\mathrm{NK} 9 / \mathrm{NK} 11$ was conducted in a thermal cycler (Perkin-Elmer) with 40 cycles of $95{ }^{\circ} \mathrm{C}$ for $15 \mathrm{~s}, 62{ }^{\circ} \mathrm{C}$ for $120 \mathrm{~s}$ and $72{ }^{\circ} \mathrm{C}$ for $40 \mathrm{~s}$. For the primer pairs NK104/NK105 as the following thermal profile was used: 40 cycles at $95{ }^{\circ} \mathrm{C}$ for $20 \mathrm{~s}, 62{ }^{\circ} \mathrm{C}$ for $60 \mathrm{~s}$ and $74{ }^{\circ} \mathrm{C}$ for $40 \mathrm{~s}$. At the conclusion of these PCR cycles, the tubes were incubated for $5 \mathrm{~min}$ at $74{ }^{\circ} \mathrm{C}$. Following completion of the PCRs, $10 \mu \mathrm{l}$ amplified product was electrophoresed in $2 \%$ agarose gel and the bands were visualized by UV transillumination.

Strains in which the $t c d A$ gene was intact yielded $1200 \mathrm{bp}$ PCR products, and $t c d A^{-} t c d B^{+}$variant strains, yielded 700 or $500 \mathrm{bp}$ PCR products. In $C$. difficile strains with an intact $t c d B^{+}$gene, the PCR product for $t c d B$ was $204 \mathrm{bp}$. 


\section{RESULTS}

The total number of $C$. difficile isolates studied was 724 . As we conducted the PCR assay for $t c d A$ and $t c d B$ retrospectively, the number of strains available was only 30 in 2000 , but the number was increased to 285 in 2005 . The prevalences of $t c d A^{+} t c d B^{+}$and $t c d A^{-} t c d B^{+} C$. difficile strains were 93.3 and $6.7 \%$ in 2000 . No $t c d A^{-} t c d B^{-} C$. difficile strain was detected in that year. However, the prevalence of the $t c d A^{+} t c d B^{+}$strain showed a tendency toward decrease from $2001(73.8 \%)$ and fell to its lowest level in 2004, as low as $35.2 \%$. In 2005, the mean prevalence of $t c d A^{+} t c d B^{+} C$. difficile was $47.7 \%$, ranging from 30.9 to $60.3 \%$. The prevalence of the $t c d A^{-} t c d B^{+}$ strain began to increase, up to $13.2 \%$ in 2003 , and finally up to $50.3 \%$ in 2004 . In 2005 , the mean prevalence of the $t c d A^{-} t c d B^{+}$strains was $27.0 \%$, ranging from 17.6 to $54.8 \%$. The $t c d A^{-} t c d B^{+}$variant strains appeared to become endemic nationwide beginning in 2005. The mean prevalence of $t c d A^{-} t c d B^{-} C$. difficile strains was approximately $22.4 \%$ for 6 years, ranging from $0 \%$ (2000) to $32.9 \%$ (2003).

Although the mean prevalences of the $t c d A^{+} t c d B^{+}$and $t c d A^{-} t c d B^{+}$C. difficile strains over the 6 years were $51.8 \%$ (range 33.3-69.9\%) and 25.8\% (range 10-56\%), the distributions of $t c d A^{+} t c d B^{+}$and $t c d A^{-} t c d B^{+}$C. difficile strains differed from hospital to hospital and from year to year (Fig. 2). In 2000, the C. difficile strains were collected only from one hospital (hospital A) and the prevalence of the variant strain in that hospital was $6.7 \%$. In 2001, isolates of $C$. difficile were acquired from two hospitals (hospitals A and B). However, the variant strains were not observed in the participating hospital in 2000, although the mean prevalence of the variant strain was $5 \%$. In 2002, the rate of prevalence of the variant strain was $4.2 \%$ (hospital

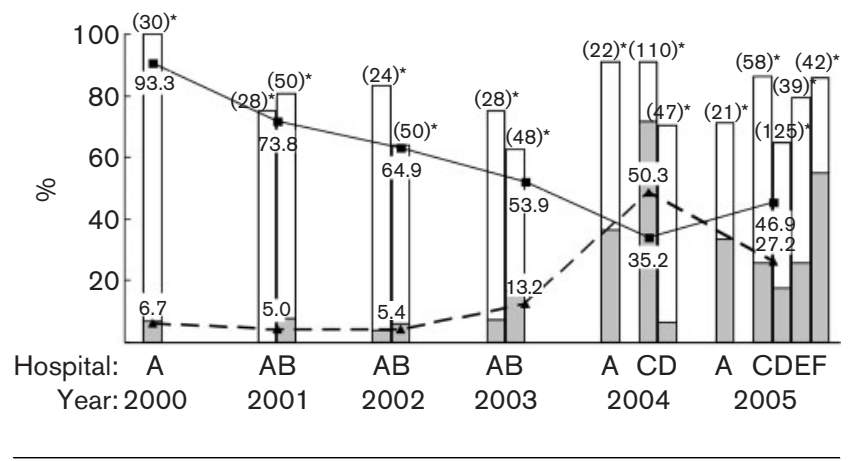

Fig. 2. The annual prevalence rate of $t c d A^{+} t c d B^{+}, t c d A^{-} t c d B^{+}$ and $t c d A^{-} t c d B^{-}$C. difficile strains in each participating hospital from 2000 to 2005. White bars, prevalence rate (\%) of $t c d A^{+} t c d B^{+}$C. difficile strain in each hospital; grey bars, prevalence rate (\%) of $t c d A^{-} t c d B^{+}$C. difficile strains in each hospital; $\mathbf{m}$ mean prevalence rate (\%) of $t c d A^{+} t c d B^{+}$C. difficile strains in all participating hospitals; $\boldsymbol{\Delta}$ mean prevalence rate (\%) of tcd $A^{-} t c d B^{+}$C. difficile strains in all participating hospitals; *, number of strains tested for each year.
A) and $6.0 \%$ (hospital B), respectively. In 2003, the prevalence of the variant strains began to increase up to $16.7 \%$ in one hospital, whereas it remained $7.1 \%$ in the other participating hospital. In 2004, another two hospitals newly participated in the surveillance (hospitals $\mathrm{C}$ and $\mathrm{D}$ ), and one hospital (hospital B) did not participate in the follow-up. One of them (hospital D) reported that the prevalence of $t c d A^{-} t c d B^{+}$C. difficile remained less than $7 \%(6.4 \%)$, but the other hospital (hospital C) reported highly prevalent $t c d A^{-} t c d B^{+}$C. difficile strains $(71.8 \%)$, suggesting an outbreak. The other continuing participating hospital (hospital A) reported an increased prevalence of $t c d A^{-} t c d B^{+}$strains $(36.4 \%)$, which was also suggestive of outbreak.

In 2005, another two hospitals (hospitals $\mathrm{E}$ and $\mathrm{F}$ ) joined the surveillance, and they already had highly prevalent $t c d A^{-} t c d B^{+}$strains (25.6 and $54.8 \%$, respectively). Their $t c d A^{+} t c d B^{+}$and $t c d A^{-} t c d B^{-}$C. difficile rates were 53.9/ $20.5 \%$ (hospital $\mathrm{E}$ ) and 30.9\%/14.3\% (hospital F), respectively.

\section{DISCUSSION}

$\mathrm{TcdA}^{-} \mathrm{TcdB}^{+}$C. difficile has been reported in several countries, with varying prevalence rates. As highly prevalent $t c d A^{-}$variant strains were previously isolated from patients with CDAD in a tertiary hospital in Korea (Shin \& Kuak, 2006; Shin et al., 2008), further nationwide surveillance was required in order to sufficiently ascertain the prevalence and virulence of $t c d A^{-} t c d B^{+}$strains of $C$. difficile in Korea. As published studies revealed no $t c d A^{-} t c d B^{+}$strains among $C$. difficile isolates in Korea (Kato et al., 1998; Rupnik et al., 2003) or lower prevalence rates $(4.3 \%)$ of these strains (Chung et al., 2002), we needed to determine at what time these $C$. difficile strains became prevalent and truly widely spread throughout Korea. This study is believed to be the first nationwide surveillance of $C$. difficile isolates from patients suspected of having CDAD in Korea.

We retrospectively obtained 724 C. difficile strains stored in each of 6 hospitals over 6 years, from 2000 to 2005. The mean prevalence of $t c d A^{-} t c d B^{+}$strains was less than $10 \%$ (range 5.5-6.7\%) until 2002, but it almost doubled $(13.2 \%)$ in 2003 and reached a maximum at 2004, with levels as high as $50.3 \%$. The mean prevalence of $t c d A^{-} t c d B^{+}$strains in 2005 was $27.0 \%$ (range 17.6$54.8 \%$ ), which was approximately four times higher than was reported in 2000 .

The prevalence rates of $\mathrm{TcdA}^{-} \mathrm{TcdB}^{+}$strains were reported to be 1.3-2\% in the USA (Lyerly et al., 1998; Geric et al., 2004) and $2.7 \%$ in France (Barbut et al., 2002). In the UK, it was estimated that approximately $3 \%$ of toxigenic $C$. difficile are $\mathrm{TcdA}^{-} \mathrm{TcdB}^{+}$strains (Brazier et al., 1999). It was identified in $11 \%$ of CDAD cases in Poland (Pituch et al., 2001). A recent 2 month prospective study in Europe in 2005 showed that $24.3 \%$ of C. difficile isolates were toxin 
variants, and the prevalence rate of toxinotype VIII was $5 \%$ overall among them (Barbut et al., 2007). By way of contrast, they reported that PCR ribotype 017 was particularly predominant in Poland, Ireland, Greece and Sweden, and all PCR ribotype 017 isolates belonged to toxinotype VIII and were $t c d A^{-} t c d B^{+}$strains. Other recent studies reported that $t c d A^{-} t c d B^{+}$strains accounted for $56 \%$ in Israel and $44 \%$ in Ireland (Samra et al., 2002; Drudy et al., 2007).

As compared with these reports, the prevalence of $t c d A^{-} t c d B^{+}$strains in Korea was less than or similar to that of the other countries until 2002-2003, but has increased since 2004. Our results revealed that outbreaks of $t c d A^{-} t c d B^{+}$strains were experienced in two hospitals in 2004; infection with these strains remained highly prevalent in 2005, as compared with published reports in Korea (Shin \& Kim,1992; Lee \& Chung, 1993; Lee et al., 1999; Kang et al., 2000; Chung et al., 2002). One hospital (hospital F), which was involved only in 2005, is located $450 \mathrm{~km}$ from other participating hospitals. However, the prevalence of $t c d A^{-} t c d B^{+}$strains in that hospital had already reached a level of $56 \%$. The prevalence of variant strains in Japan was reported to be $12.5 \%$ (Kato et al., 1998). However, variant prevalence rates as high as $39 \%$ during a 1 year period (December 1999-November 2000) have been reported in CDAD patients, although this was a report issued by a Japanese hospital (Komatsu et al., 2003). These results suggested that $t c d A^{-} t c d B^{+}$strains had spread throughout Far East Asia, including Korea and Japan, before 2000, and these $t c d A^{-} t c d B^{+}$strains appeared to be endemic in many Korean hospitals since 2004.

We are not currently precisely certain as to why we had such highly prevalent $t c d A^{-} t c d B^{+}$strains in Korea over such a brief duration of time. We surmised that one reason might be that patients are constantly on the move seeking better medical service, and C. difficile is a pathogen that is quite difficult to eradicate, because of its ability to sporulate (McFarland et al., 1989). Another factor may be a failure of infection control due to the lack of awareness of the physicians involved. It appears likely that, at some point, there must have been a clinical sign of a $C$. difficile variant. However, we may have missed this because we did not possess adequate data regarding the nationwide prevalence of $C$. difficile variants prior to 2005, because culturing, $C$. difficile is a strenuous procedure in the majority of laboratories, and EIAs for TcdA only have been widely utilized for the diagnosis of $C$. difficile infection in Korea, as has been reported in other European countries (Barbut et al., 2003). These commercial toxin A EIAs are not capable of detecting $t c d A^{-} t c d B^{+}$variants, as variant strains of $C$. difficile that harbour deletions of $1.7-1.8 \mathrm{~kb}$ in tcdA yielded no detectable TcdA (Kato et al., 1998; Von Eichel-Streiber et al., 1999; Rupnik et al., 1997). Therefore, no attention appeared to be paid previously to infection control, especially with regard to $t c d A^{-} t c d B^{+} C$. difficile strains. Another factor to be considered is that the diagnostic algorithms of CDAD differ from hospital to hospital. Therefore, these outbreaks appear to be associated with delays in CDAD diagnosis in certain hospitals. All of these factors may result in a significant burden on the health-care system associated with CDAD (Riley et al., 1995).

In conclusion, this nationwide epidemiological study showed that $t c d A^{-} t c d B^{+}$C. difficile strains have already spread widely in Korea, and EIAs capable of detecting both TcdA and TcdB should be utilized in microbiology laboratories in order to control these strains of $C$. difficile in Korea.

\section{REFERENCES}

Al-Barrak, A., Embil, J., Dyck, B., Olekson, K., Nicoll, D., Alfa, M. \& Kabani, A. (1999). An outbreak of toxin A negative, toxin B positive Clostridium difficile-associated diarrhea in a Canadian tertiary-care hospital. Can Commun Dis Rep 25, 65-69.

Alfa, M. J., Kabani, A., Lyerly, D., Moncrief, S., Neville, L. M., alBarrack, A., Harding, G. K. H., Dyck, B., Olekson, K. \& Embil, J. M. (2000). Characterization of a toxin A-negative, toxin B-positive strain of Clostridium difficile responsible for a nosocomial outbreak of Clostridium difficile-associated diarrhea. J Clin Microbiol 38, 27062714.

Barbut, F., Lalande, V., Burghoffer, B., Thien, H. V., Grimprel, E. \& Petit, J. C. (2002). Prevalence and genetic characterization of toxin A variant strains of Clostridium difficile among adults and children with diarrhea in France. J Clin Microbiol 40, 2079-2083.

Barbut, F., Delmee, M. \& Brazier, J. S. (2003). A European survey of diagnostic methods and testing protocols for Clostridium difficile. Clin Microbiol Infect 9, 989-996.

Barbut, F., Mastrantonio, P., Delmee, M., Brazier, J., Kuijper, E. \& Poxton, I. on behalf of the European Study Group on Clostridium difficile (ESGCD) (2007). Prospective study of Clostridium difficile infection in Europe with phenotypic and genotypic characterization of the isolates. Clin Microbiol Infect 13, 1048-1057.

Braun, V., Hundsberger, T., Leukel, P., Sauerborn, M. \& von EichelSteiber, C. (1996). Definition of the single integration site of the pathogenicity locus in Clostridium difficile. Gene 181, 29-38.

Brazier, J. S., Stubbs, S. L. J. \& Duerden, B. I. (1999). Prevalence of toxin A-negative/B-positive Clostridium difficile strains. J Hosp Infect 42, 248-249.

Chung, Y., Chung, G. T., Seong, W. K. \& Oh, H. B. (2002). Molecular analysis of Clostridium difficile isolates by arbitrarily primedpolymerase chain reaction and polymerase chain reaction-ribotyping. Korean J Infect Dis 34, 167-175.

Cohen, S. H., Tang, Y. J. \& Silva, J., Jr (2000). Analysis of the pathogenicity locus in Clostridium difficile strains. J Infect Dis 181, 659-663.

Drudy, D., Harnedy, N., Fanning, S., O'Mahony, R. \& Kyne, L. (2007). Isolation and characterization of toxin A negative, toxin B positive Clostridium difficile in Dublin, Ireland. Clin Microbiol Infect 13, 298304.

Geric, B., Rupnik, M., Gerding, D., Grabnar, M. \& Johnson, S. (2004). Distribution of Clostridium difficile variant toxinotypes and strains with binary toxin genes among clinical isolates in an American hospital. J Med Microbiol 53, 887-894.

Hammond, G. A. \& Johnson, J. L. (1995). The toxigenic element of Clostridium difficile strains VPI 10463. Microb Pathog 19, 203-213. 
Johnson, S., Kent, S. A., O'Leary, K. J., Merrigan, M. M., Sambol, S. P., Peterson, L. R. \& Gerding, D. N. (2001). Fatal pseudomembranous colitis associated with a variant Clostridium difficile strain not detected by toxin A immunoassay. Ann Intern Med 135, 434-438.

Kang, J. O., Chae, J. D., Eom, J. I., Han, D., Park, P. W., Park, I. K. \& Choi, T. Y. (2000). Comparison of Clostridium difficile toxin A immunoassay with cytotoxicity assay. Korean J Clin Microbiol 3, 43-47.

Kato, H., Kato, N., Watanabe, K., Iwai, N., Nakamura, H., Yamamoto, T., Suzuki, S., Kim, S. M., Chong, Y. \& Wasito, E. B. (1998). Identification of toxin A negative, toxin $\mathrm{B}$ positive Clostridium difficile by PCR. J Clin Microbiol 36, 2178-2182.

Komatsu, M., Kato, H., Aihara, M., Shimakawa, K., Iwasaki, M., Nagasaka, Y., Fukuda, S., Matsuo, S., Arakawa, Y. \& other authors (2003). High prevalence of antibiotic-associated diarrhea due to toxin A negative, toxin B positive Clostridium difficile in a hospital in Japan and risk factors for infection. Eur J Clin Microbiol Infect Dis 22, 525-529.

Kuijper, E. J., Weerdt, J., Kato, H., Kato, N., Dam, A. P., Vorm, E. R., Weel, J., Rheenen, C. \& Dankert, J. (2001). Nosocomial outbreak of Clostridium difficile associated diarrhea due to a clindamycin resistant enterotoxin A negative strain. Eur J Clin Microbiol Infect Dis 20, $528-534$.

Lee, H. J. \& Chung, Y. (1993). Toxin test and quantitative culture of stool for the diagnosis of Clostridium difficile associated diseases. Korean J Clin Pathol 13, 461-466.

Lee, H. M., Kim, Y. A., Park, K. I., Lee, K. W. \& Chung, Y. (1999). Detection of toxin $\mathrm{B}$ gene of Clostridium difficile by polymerase chain reaction from clinical isolates. Korean J Clin Microbiol 2, 77-81.

Limaye, A. P., Turgeon, D. K., Cookson, B. T. \& Fritsche, T. R. (2000). Pseudomembranous colitis caused by a toxin $\mathrm{A}^{-} \mathrm{B}^{+}$strain of Clostridium difficile. J Clin Microbiol 38, 1696-1697.

Lyerly, D. M., Neville, L. M., Evans, D. T., Fill, J. \& Allen, S. (1998), Multicenter evaluation of the Clostridium difficile TOX A/B test. J Clin Microbiol 36, 184-190.

McFarland, L. V., Mulligan, M. E., Kwok, R. Y. \& Stamm, W. E. (1989). Nosocomial acquisition of Clostridium difficile infection. $N$ Engl J Med 320, 204-210.
Pituch, H., van den Braak, N., van Leeuwen, W., van Belkem, A., Martirosian, G., Obuch-Woszczatynski, P., Luczak, M. \& MeiselMikolajczyk, F. (2001). Clonal dissemination of a toxin A negative/ toxin B positive Clostridium difficile strain from patients with antibiotic associated diarrhea in Poland. Clin Microbiol Infect 7, 442-446.

Riley, T. V., Codde, J. P. \& Rouse, I. L. (1995). Increased length of hospital stay due to Clostridium difficile associated diarrhoea. Lancet 345, 455-456.

Rupnik, M. (2001). How to detect Clostridium difficile variant strains in a routine laboratory. Clin Microbiol Infect 7, 417-420.

Rupnik, M., Braun, V., Soehn, F., Janc, M., Hofstetter, M., Laufenberg-Feldmann, R. \& von Eichel-Streiber, C. (1997). Characterization of polymorphisms in the toxin A and B genes of Clostridium difficile. FEMS Microbiol Lett 148, 197-202.

Rupnik, M., Avesani, V., Janc, M., von Eichel-Streiber, C. \& Delmee, M. (1998). A novel toxinotyping scheme and correlation of toxinotypes with serogroups of Clostridium difficile isolates. J Clin Microbiol 36, 2240-2247.

Rupnik, M., Kato, N., Grabnar, M. \& Kato, H. (2003). New types of toxin A-negative, toxin B-positive strains among Clostridium difficile isolates from Asia. J Clin Microbiol 41, 1118-1125.

Samra, Z., Talmor, S. \& Bahar, J. (2002). High prevalence of toxin A negative toxin B positive Clostridium difficile in hospitalized patients with gastrointestinal disease. Diagn Microbiol Infect Dis 43, 189-192.

Shin, B. M. \& Kim, E. C. (1992). SDS-PAGE profiles of Clostridium difficile isolated from patients and hospital environments. Korean $\mathrm{J}$ Clin Pathol 12, 223-232.

Shin, B. M. \& Kuak, E. Y. (2006). Characterization of a toxin A negative and toxin B positive variant strain of Clostridium difficile. Korean J Lab Med 26, 27-31.

Shin, B. M., Kuak, E. Y., Yoo, S. J., Shin, W. C. \& Yoo, H. M. (2008). Emerging toxin $\mathrm{A}^{-} \mathrm{B}^{+}$variant strain of Clostridium difficile responsible for pseudomembranous colitis at a tertiary care hospital. Diagn Microbiol Infect Dis 60, 333-337.

Von Eichel-Streiber, C., Zec-Pirnat, I., Grabnar, M. \& Rupnik, M. (1999). A nonsense mutation abrogates production of a functional enterotoxin A in Clostridium difficile toxinotype VIII strains of serogroups F and X. FEMS Microbiol Lett 178, 163-168. 